\title{
Selection institutions and war aims
}

\author{
James D. Morrow ${ }^{1}$, Bruce Bueno de Mesquita $^{2}$, Randolph M. Siverson ${ }^{3}$, \\ Alastair Smith ${ }^{4}$ \\ 1 University of Michigan, 4203 ISR, 426 Thompson St., Ann Arbor, MI 48106-1248, USA \\ (e-mail: jdmorrow@umich.edu) \\ 2 Hoover Institution, Stanford, CA 94305-6010, USA \\ 3 Department of Political Science, University of California, Davis, One Shields Ave, Davis, \\ CA 95616, USA \\ 4 Department of Politics, New York University, 715 Broadway, 4th floor, NY, NY 10003, USA
}

Received June 2004 / Accepted April 2005

\begin{abstract}
We explore how the sizes of the winning coalition and selectorate influence the war aims of states. Leaders who answer to a small winning coalition are more likely to seek territorial gain as a way to increase state resources. Nonterritorial war aims produce a commitment problem in that after the war the defeated state may not comply with the victor's demands. States with large winning coalitions are more willing to continue the war to remove the enemy leader as a solution to this commitment problem. We test our hypotheses against the Militarized Interstate Dispute data set, and we find some support for our argument.
\end{abstract}

Key words: Winning coalition, war aims, postwar commitment problem, interstate conflict

Domestic political institutions shape public policy by creating incentives for political leaders to pursue different policies. In this paper, we examine how the selection institutions of a state - how it removes and replaces leaders - influence the aims that its leaders pursue through war. We characterize selection institutions in a simple and very general way using two concepts; the winning coalition: the set of people whose support the leader must hold to retain power; and the selectorate: the pool of people from whom a challenger could create a new winning coalition. A leader uses public policy to reward his or her winning coalition by providing those supporters with public goods and private benefits. Our central intuition about selection institutions is that the size of the winning coalition acts as the price of providing private benefits to the members of the winning coalition. The more supporters a leader must please, the more expensive it is to provide them with private benefits, and so the leader shifts the mixture of goods produced by public policy away from private benefits and towards public goods. Thus, leaders who answer to a large winning coalition focus their policy more on the provision of public goods than those who 
answer to a small winning coalition. In our book, The Logic of Political Survival (Bueno de Mesquita et al. 2003), we examine a wide range of governance issues in both domestic and foreign policy using this argument. We expand the discussion of how selection institutions shape war aims in this paper.

Foreign policy can produce either private benefits or public goods for supporters. Historically, loot has been used in war to reward those who fight, although its role has declined over time. Security of both people and their property is the central public good of foreign policy, precisely because external forces pose a threat to both. Ideological goals also create public goods as none in society can be denied the benefits of humanitarian ends. Among war aims, territorial expansion can produce either the public good of security or increase the ability of the leader to provide private benefits to supporters through the expansion of state resources. Seizing strategic locations could increase the personal security of the residents of a state by making the territory of the state more defensible. Territorial expansion into areas with productive populations or valuable natural resources increase the resources available to the leader, allowing him or her to provide more private benefits to supporters. Extending our point about how the size of the winning coalition affects policy, we expect that leaders who answer to a small winning coalition are more likely to seek territorial expansion for resources; those who answer to a large winning coalition are more likely to seek increased security or ideological goals.

Broad policy aims in war face a commitment problem in that they often require the active participation of the defeated state to secure those aims in the future. Such cooperation from the defeated state creates a commitment problem in that the government of the losing state may not wish to carry out the actions it pledged to end the war. Instead, it may refuse to cooperate with the victorious state, thereby denying the victor the fruits of its victory. All war aims face this problem to some extent because the defeated state can threaten war anew to overturn the result of its defeat. However, policy aims face this commitment issue more directly because they often require the active participation of the defeated for the victor to realize its war aims. The loser can thwart the victor even without renewing the war.

The losing government may face political pressure to overturn the postwar status quo. Postwar settlements are often unpopular in the losing state. Challengers to the leader may be able to use revision of the postwar settlement as an issue in their efforts to supplant the leader. This issue is more effective when the settlement is unpopular and those opposed to it have a clear voice in the political process of the defeated state. The commitment problem of winning the peace then becomes more significant as the size of winning coalition needed to hold power in the losing state grows. If the losing leader answers only to a small group of supporters, he can placate their demands to overturn the peace settlement by providing them with private benefits. When the losing leader must answer to a large coalition, he may have to adopt a policy of international revision to forestall a challenger using that issue against him.

The victorious leader can solve this commitment problem by replacing the defeated leader and installing a puppet in the defeated state. A puppet government solves the commitment problem by eliminating the incentive to pursue revisionist demands by defusing them in the domestic politics of the defeated state. This course 
requires a complete defeat of the losing state in order for the victor to overthrow the defeated regime, making it more costly than a negotiated settlement that achieves the assent of the defeated to the war aims of the victorious leader. The leader of a state winning a war then faces a choice: settle now but face the possibility that the losing leader will renege on its concessions on policy issues after the war is over or fight to the collapse of the defeated state's troops, allowing you to impose a leader of your choice on the defeated state, countering the commitment problem after the war is over.

A small winning coalition in the defeated state reduces the commitment problem. As noted above, the leader of such a system can follow the policies preferred by the victor and still retain power by providing his or her small number of supporters with private benefits even his or her foreign policy is unpopular with his or her winning coalition. Doing so may be in the interest of the losing leader as a way to avoid further confrontation with the victor. The continued threat of the victor to renew the war and overthrow the defeated leader might be sufficient to induce unpopular compliance by the defeated leader. In the extreme, the leader of a weaker state might be able to avoid war entirely by making policy concessions before fighting began.

Our essential point is that the selection institutions of both states, victor and vanquished, play a key role in determining war aims. During the war, leaders who answer to a large winning coalition are more likely to seek policy ends over territory compared to those who answer to a small winning coalition. In the defeated state, a leader who answers to a large winning coalition is more likely to feel pressure to pursue revisionist policies after the war, exacerbating the commitment problem posed by policy aims in war. In turn, the victorious leader will care more about solving this commitment problem when he answers to a large winning coalition, and so will be more likely to fight until the enemy regime is overthrown and replaced by one that will not work to subvert the peace after the war.

We have developed this argument in Chapter 9 of The Logic of Political Survival with a simple model and a range of evidence. Here we extend the argument by (1), presenting a general model of the argument, and (2), additional tests of the conclusions of that argument. We also hope to bring this argument to the attention of those who are not yet aware of it, and in doing so, show how political economy arguments can be applied fruitfully to think about international conflict.

\section{The model}

Two states, $\mathbf{A}$ and $\mathbf{B}$, are fighting each other in a war, with $\mathbf{A}$ winning. Each has a leader, $A$ and $B$ respectively. Each state begins with a pool of resources, $R_{A}$ and $R_{B}$ respectively. The selection institutions of each state are given by the sizes of the winning coalition, $W_{A}$ and $W_{B}$, and the selectorate, $S_{A}$ and $S_{B}$; we refer to representative members of the selectorate in each state as $\alpha$ and $\beta$. Each leader will face a challenger, $a$ and $b$, in the rounds of the game after the war ends. Full details of the model, including the comparative statics behind the hypotheses, can be found in the Appendix ${ }^{1}$ to the paper.

\footnotetext{
1 See http://sitemaker.umich.edu/jdmorrow/files/berlinapp.pdf
} 
The model begins with a decision by $A$ whether to (1) end the war imposing no changes in territory or regime, (2) take territory containing resources $r$ from $\mathbf{B}$, (3) continue the war to replace $B$ with a puppet and changing $W_{B}$ and $S_{B}$ at the same time, or (4) continue the war to replace $B$ and take territory from $\mathbf{B}$. Adding territory imposes a cost of $C_{r}$ on $A$; we think of these costs as governance costs for absorbing the territory into A (cf. Lake 1999). Overthrowing $B$ will extend the war, requiring $A$ to pay added costs of war $C_{D}$ (for depose). Taking territory and overthrowing $B$ imposes both costs on $A$ as the war is prolonged and then $A$ must pay governance costs for the added territory after the war is over. $A$ then has four choices in its first move; end the war now, continue to fight to gain territory $r$ from $\mathbf{B}$ at cost $C_{r}$, continue to fight to depose $B$ at $\operatorname{cost} C_{D}$, or take territory $r$ and depose $B$ at total cost $C_{r}+C_{D}$. If $A$ takes territory, the resources of the two states will be $R_{A}+r$ and $R_{B}-r$ respectively. If $A$ deposes $B, A$ can set $W_{B}$ and $S_{B}$.

After $A$ 's initial decision on war aims and when to end the war, regular politics within and between the two states is represented by repeated rounds of a selection process. As the selection process is the same in both states, we drop the subscripts denoting state in this discussion to reduce clutter, but the reader should remember that all these variables are specific to each state. In each round in each state, first the leader allocates state resources to three goods, private benefits, $g$, domestic public goods, $x$, and foreign policy, $p$, where the foreign policy is viewed as a public good. The leader also specifies a winning coalition from the set of selectors in his country when proposing his allocation of resources. The leader has a preference order over the selectors in terms of which of them he would like to include in his winning coalition; we refer to this preference order as the leader's affinity for selectors. A challenger is selected at random from the set of all possible affinities with a uniform distribution, and she offers an allocation of state resources to $g, x, p$ and proposes her own winning coalition. Based on these proposals, the members of the selectorate choose either the leader or the challenger. The leader is retained in office if at least $W$ members of his proposed winning coalition select him or if less than $W$ members of the challenger's proposed winning coalition select her. The winner implements its proposal with all players receiving payoffs. The leader and challenger value holding office and the amount of resources they can retain for their own purposes; $u=\Theta+R-m$ (where $m=|W| g+x+p$, the resources promised to create private benefits, public goods, and foreign policy and $|W|$ is the cardinality of the winning coalition) if selected as leader, 0 not. The discretionary resources the leader commands could be used simply for his own material benefit or for pet projects. No matter what their use, leaders prefer having more resources that they can use as they wish. These rounds of selection are repeated indefinitely with a successful challenger becoming the leader in the next round; future payoffs are discounted by a common discount factor of $\delta$ per round.

Whether selectors choose to retain the leader depends on the attractiveness of what the leader and challenger offer them now in this round and can be expected to offer them in future rounds. Private benefits are assumed to be equal shares paid to each member of the winner's winning coalition, while all in society receive the public goods produced by the winner. Foreign policy is a public good where the amount of the good provided increases with the resources your own leader commits 
to it and decreases with the resources the leader of the other country commits to foreign policy. Specifically, the foreign policy outcome is $f=\mathrm{B}_{A} p_{A}+\mathrm{B}_{B} p_{B}$ with $\mathrm{B}_{A}>0$ and $\mathrm{B}_{B}<0$, with $\mathrm{B}_{A}$ and $\mathrm{B}_{B}$ giving how effectively each state turns resources into favorable foreign policy outcomes. $\mathbf{A}$ and $\mathbf{B}$ are in a classic security dilemma (cf. Jervis 1978) because the resources that make one more secure make the other less secure. Those in A prefer larger values of $f$ while those in $\mathbf{B}$ prefer smaller values. Preferences over the three goods are given by utility functions $U_{A}\left(x_{A}, g_{A}, f\right)$ and $U_{B}\left(x_{B}, g_{B}, f\right)$ which are increasing, concave, and additively separable in their arguments. Further, we assume that preferences are such that leaders will always provide a mix of all three goods rather than a corner solution.

Selectors must consider not only the immediate policy promises of the current leader and challenger, but also the consequences of each holding power in the future. Members of the winning coalition of the winner receive private benefits in addition to the commonly received benefits of public goods and foreign policy. Membership in the winning coalition over time is important, and the incumbent leader has an important advantage over the challenger in the credibility of a promise to keep the same winning coalition over time if he retains office. Members of the current leader's winning coalition can be confident that they will continue to receive private benefits as long as the current leader is in power. The challenger, however, has no record of loyalty to her proposed winning coalition, and so members of it may doubt whether she will retain them if she comes to power. After all, the challenger may be willing to promise anything to come to power, but what will she deliver once there? We model this by assuming that both the leader and the challenger have a preference ordering over members of the selectorate, which we call affinities. All else equal, the leader prefers including higher ranked selectors in his winning coalition, and the challenger does not learn her affinities for selectors until she comes to power. This simple artifice introduces this commitment problem because the incumbent leader can choose the selectors he has highest affinity for as his winning coalition, and they will then understand that he will continue to do so in future rounds because of his affinity for them. However, the members of the challenger's proposed winning coalition do not know if she will exclude them in favor of others in the next round if she wins and becomes leader.

The sequence of selection processes, first in $\mathbf{A}$, then in $\mathbf{B}$, captures the commitment problem that the leader of $\mathbf{A}$ faces in getting $\mathbf{B}$ to cooperate after the war is over. Because the foreign policy of $\mathbf{B}$ is set after that of $\mathbf{A}$, both $A$ and a must account for B's independence in setting its foreign policy when they make their own decisions about foreign policy. Further, the internal selection process provides leaders and challengers in both states with incentives to pursue different war aims. Fighting to gain territory increases A's resources and decreases B's resources; however, leaders value this shift in resources because of the changes it has in their ability to retain power and resources for themselves. For $A$, the value in deposing $B$ lies in the power to shape the selection institutions of $\mathbf{B}$ to reduce the incentive any leader of $\mathbf{B}$ has to challenge $\mathbf{A}$ on foreign policy in the future. The model analyzes how the ends leaders pursue in war are influenced by the domestic politics of the post-war period. 


\section{Taking territory and deposing leaders in equilibrium}

The willingness of $A$ to pursue territorial gain, the deposition of $B$, or both depends on what he would gain politically after the war from those ends. $A$ 's decision hinges on a comparison of the costs versus the benefits of each course. The following are $A$ 's payoff for each of the four possibilities:

$$
\begin{aligned}
& \text { Neither: } \Theta_{A}+R_{A}-m_{A}^{*} \\
& \text { Territory: } \Theta_{A}+R_{A}+r-m_{A}^{+}-C_{r} \\
& \text { Overthrow } B: \Theta_{A}+R_{A}-m_{A}^{\wedge}-C_{D} \\
& \text { Territory and Overthrow: } \Theta_{A}+R_{A}+r-m_{A}^{\widetilde{N}}-C_{r}-C_{D}
\end{aligned}
$$

where $m_{A}^{*}$ is the amount of resources $A$ commits to $g, x, p$ under the original distribution of resources and selection institutions in $\mathbf{B}, m_{A}^{+}$is the amount of resources that $A$ commits after shifting $r$ resources from $\mathbf{B}$ to $\mathbf{A}, m_{A}^{+}$is the amount of resources that $A$ commits after changing $W_{B}$ and $S_{B}$ after overthrowing $B$, and $m_{A}$ is the amount of resources that $A$ commits after shifting $r$ resources from $\mathbf{B}$ to $\mathbf{A}$ and changing $W_{B}$ and $S_{B}$. A will choose the option that produces the highest value among these four options.

The structure of choices and their benefits and costs allows us to consider decisions whether to take territory and whether to overthrow the enemy leader separately. Strictly speaking, the decisions cannot be separated, but the decision considerations underlying each choice are the same regardless of the choice on the other. So if $A$ will not overthrow $B, A$ will prefer to take territory from $\mathbf{B}$ when

$$
r-m_{A}^{+}+m_{A}^{*}>C_{r}
$$

If $A$ will overthrow $B, A$ will prefer to take territory from $\mathbf{B}$ when

$$
r-m_{A}^{\tilde{A}}+m_{A}^{\wedge}>C_{r}
$$

In both cases, the benefit of territorial expansion is the left-hand side of inequality (2), which is the amount of the added resources that the leader retains for his own purposes. The cost is the right-hand side.

Territorial expansion to add resources has a direct effect of increasing the resources of $\mathbf{A}$ and an indirect effect of decreasing the resources of $\mathbf{B}$. The direct effect becomes smaller as the leader needs to commit more resources to policy to retain power. A reduction in the resources of $\mathbf{B}$ benefits all those in $\mathbf{A}$ by reducing the amount of resources the leader of $\mathbf{B}$ commits to foreign policy. The leader of $\mathbf{A}$ in turn can then direct resources away from foreign policy and towards domestic goods, including his own discretionary resources. The indirect effect becomes smaller as the leader of $\mathbf{B}$ commits fewer resources to foreign policy. It becomes more important to $A$ as $A$ commits more resources to foreign policy in equilibrium.

The willingness of $A$ to depose $B$ and change $W_{B}$ and $S_{B}$ as he chooses also depends on the political benefits $A$ gains after the war from that change. The following inequality specifies when $A$ will depose $B$ when $A$ will not take territory:

$$
m_{A}^{*}-m_{A}^{\wedge}>C_{D}
$$


$A$ will depose $B$ when $A$ will take territory:

$$
m_{A}^{\tilde{A}}-m_{A}^{+}>C_{D}
$$

The left-hand side in both cases is the savings in resources that $A$ realizes from the deposition of $B$. This effect is entirely indirect; all those in $A$ benefit if $\mathbf{B}$ devotes fewer resources to foreign policy both by obtaining a better outcome in foreign policy while committing fewer resources. As above, the indirect effect becomes more important as the leaders of both $\mathbf{A}$ and $\mathbf{B}$ commit more resources to foreign policy in equilibrium.

For both decisions, the specifics of each depend upon the other as the benefits of taking territory depend upon whether the enemy leader is removed and vice versa. Nevertheless, the direct and indirect benefits of taking territory and the indirect benefit from deposing the enemy leader vary with the selection institutions of both states in the same way regardless of whether $A$ does the other. The question for $A$ is both cases is whether the benefits exceed the costs. We assume the costs are fixed across selection institutions in both states as we have no a priori argument about how the costs of taking territory or deposing leaders vary with selection institutions. Our hypotheses then depend on how the direct and indirect effects here change with the selection institutions of $\mathbf{A}$ and $\mathbf{B}$, which we now discuss in general as the principles are the same in both states. After doing so, we consider when $A$ would consider doing both.

\section{Selection institutions and policy}

The selection institutions drive the policy choices, that is resource allocations, of the leader and challenger through the size of the winning coalition and the selectorate, the pool of people from which the challenger could create her winning coalition. Both will allocate resources efficiently across $g, x, p$ to produce maximal utility for the members of their proposed winning coalition. The leader strives to retain the loyalty of his winning coalition, while the challenger must pull off enough members of that coalition to reduce it below $W_{A}$ and also assemble a coalition of at least that size. Critical to this process is the pivotal member of the leader's winning coalition whose defection would bring down the incumbent leader. The best offer the challenger can make is to commit all resources to $g, x, p$ efficiently across the three goods. The incumbent need only commit sufficient resources to policy so that this pivotal member of his winning coalition will not prefer defecting to the challenger. The following inequality, known as the incumbency condition, specifies how many resources the leader needs to retain the loyalty of this pivotal member:

$$
\begin{aligned}
(1-\delta)[ & U(x, g, f(p))-V(R)] \\
& +\delta(1-W / S)[U(x, g, f(p))-U(x, 0, f(p))] \geq 0
\end{aligned}
$$

where $x, g, p$ are the equilibrium allocations of the incumbent and $V(R)$ is the utility produced by an optimal allocation of all resources $R$ to $x, g, p$. The incumbency 
condition follows from a comparison of the pivotal selector's utility for choosing the leader and that for choosing the challenger. The first term of (6) compares the current allocation of the incumbent and the challenger, where presumably the incumbent offers less in this period. The second term compares what the pivotal selector expects in the future from each. As the pivotal selector is a member of the incumbent's winning coalition, he expects to continue to be in the winning coalition - meaning he will receive private benefits in the future - if the incumbent is retained. If the challenger comes to power, the chance that the pivotal selector will be in the challenger's winning coalition in the future is $W / S$ because no one, the challenger included, knows yet whether the challenger will want to include the pivotal selector in her winning coalition in the future. The term $1-W / S$ then gives the risk of exclusion that the pivotal selector faces if he defects from the incumbent leader to the challenger. This risk of exclusion allows the incumbent to commit fewer resources than the challenger and still satisfy incumbency condition (6).

The primary effect of selection institutions on optimal allocations of resources to policy in the light of the incumbency condition is that increases in the size of the winning coalition shift resources from private benefits into public goods and foreign policy. This is a price effect; the size of the winning coalition acts as the price for providing private benefits to the winning coalition. This shift toward public goods and foreign policy (which is a public good in this model) lowers the difference between being in and out of the winning coalition; it reduces the second term of the incumbency condition (6), forcing the incumbent leader to commit more resources to lessen the difference in the first term. Leaders who answer to a larger winning coalition commit more resources to foreign policy and must commit more resources to policy overall.

The size of the selectorate plays a secondary role here through the risk of exclusion. As $S$ increases, $1-W / S$ also increases, placing more weight on the second term of the incumbency condition. Increases in the selectorate then allow the leader to commit fewer resources to match the challenger. However, this effect is stronger when $W$ is small. When $W$ is large, the incumbent produces fewer private benefits for each member of his winning coalition, reducing the effect of the risk of exclusion. Historically, increases in the size of the selectorate have accompanied increases in the size of the winning coalition, effectively keeping $W / S$ fixed. For example, expansion of suffrage in late $19^{t h}$ and early $20^{t h}$ centuries expanded both while keeping their ratio fixed.

\section{Selection institutions and war aims}

$A$ always benefits from the additional resources by adding territory or from the reduction in foreign policy effort induced by overthrowing $B$; the key question is does $A$ benefit enough from these war aims to justify their added cost? The answer to this question depends on how many resources $A$ can retain for his own purposes. Taking territory, as explained above, has a direct and indirect effect on the leader's share of the resources. The direct effect comes from the added resources $\mathbf{A}$ has. The greater the share of these added resources that $A$ can keep for his own purposes, the more attractive taking territory is, all else equal. The share of resources that $A$ 
retains decreases as $W_{A}$ increases and as $S_{A}$ decreases. Further, the effect of $W_{A}$ is larger than that of $S_{A}$. Consequently, $A$ is less willing to take territory as $W_{A}$ and $S_{A}$ both increase in a fixed proportion.

The indirect effect of taking territory arises from the reduction in the resources of $\mathbf{B}$ and so the amount of resources that the leader of $\mathbf{B}$ commits to foreign policy. $B$ commits more resources to foreign policy the larger $W_{B}$ and the smaller $S_{B}$, all else equal. The indirect effect of taking territory is greater, and $A$ more willing to take territory, as $W_{B}$ increases and $S_{B}$ decreases. Here the two effects are in the proportion of $W_{B} / S_{B}$, so $A$ 's willingness to take territory from $\mathbf{B}$ does not change if they grow in proportion. This indirect effect is larger when $A$ puts more resources into foreign policy, so the indirect benefit to $A$ increases as $W_{A}$ increases and $S_{A}$ decreases.

Of these two effects, the direct effect dominates the indirect effect. Then $A$ is more likely to take territory as

1. The size of winning coalition in $\mathbf{A}$ decreases,

2. The size of the selectorate in $\mathbf{A}$ increases,

3. The size of the winning coalition in $\mathbf{B}$ increases,

4. The size of the selectorate in $\mathbf{B}$ decreases, and

5. The effect of the size of the winning coalition in $\mathbf{A}$ on whether $A$ takes territory is greater than the effect of the size of the selectorate in $\mathbf{A}$.

The effect of the relative resources of the two sides is complicated because of the combination of direct and indirect effects. First, the stronger $\mathbf{A}$ is relative to $\mathbf{B}$, the lower the cost of taking territory, and hence the more likely that $A$ will do so. This is a direct effect, as is any proportion of the taken resources that $A$ can retain for his own uses after producing private benefits, public goods and foreign policy. Second, the indirect effect of taking territory containing resources comes from the reduction in resources that $B$ has to commit to foreign policy in the future. The more resources $\mathbf{B}$ has, the greater this effect, so the indirect benefit of taking territory decreases as A's resources grow relative to $\mathbf{B}$. Additionally, the indirect effect looms larger in $A$ 's decision as the size of the winning coalition in $\mathbf{A}$ increases. $A$ commits more resources to foreign policy as the size of the winning coalition in $\mathbf{A}$ increases, making the benefits of reducing the resources of $\mathbf{B}$ greater to $A$. This indirect effect goes counter to the direct effect of lower cost. We cannot say which effect is larger in general, but we can conclude that the effect of the power of $\mathbf{A}$ relative to $\mathbf{B}$ on $A$ 's willingness to take territory from $\mathbf{B}$ should decrease as the size of the winning coalition in $\mathbf{A}$ increases. Then $A$ is more likely to take territory from $\mathbf{B}$ as

6. The power of $\mathbf{A}$ increases relative to $\mathbf{B}$, and

7. This effect decreases as the size of the winning coalition in $\mathbf{A}$ increases.

Deposing $B$ has only indirect effects for $A$. As with the indirect effect of taking territory, $A$ is more willing to depose $B$ as $W_{A}$ increases and $S_{A}$ decreases. $A$ is also more willing to depose $B$ as $W_{B}$ increases and $S_{B}$ decreases. Here again both sets of the effects are in the proportion of $W / S$, so $A$ 's willingness to overthrow $B$ does not change if $W_{A}$ and $S_{A}$ or $W_{B}$ and $S_{B}$ grow in proportion. Then $A$ is more likely to depose $B$ as 
8. The size of winning coalition in $\mathbf{A}$ increases,

9. The size of the selectorate in $\mathbf{A}$ decreases,

10. The size of the winning coalition in $\mathbf{B}$ increases, and

11. The size of the selectorate in $\mathbf{B}$ decreases.

The relative power of the two sides primarily enters $A$ 's decision whether to overthrow $B$ through the cost of doing so. Deposing $B$ requires a total victory by $\mathbf{A}$ which is unlikely and certain to be very costly if $\mathbf{A}$ is weaker than $\mathbf{B}$. Consequently, $A$ 's willingness to depose $B$ should increases as

\section{The power of $\mathbf{A}$ relative to $\mathbf{B}$ increases.}

If $A$ deposes $B$, he will want to impose selection institutions in $\mathbf{B}$ that give the leader of $\mathbf{B}$ the least incentive to commit resources to foreign policy. The smallest possible winning coalition and the largest possible selectorate for $\mathbf{B}$ does this. In reality, $A$ may not have freedom to choose $W_{B}$ to be as small as possible and $S_{B}$ as large as possible. We do expect that $A$ will seek to reduce the ratio $W_{B} / S_{B}$ when changing the selection institutions in $\mathbf{B}$ as reductions in that ratio reduce the amount of resources the leader of $\mathbf{B}$ will commit to foreign policy.

The hypotheses above compare the attraction of taking territory and deposing the enemy leader against doing neither. We also need to compare these war aims against one another as it is conceivable that $A$ prefers both to doing neither. It is conceivable that changes that increase the benefits of one type of war aim might increase the benefits of the other even more, and so confound our hypotheses above. The comparison of these two war aims depends on how the benefits of taking territory and deposing $B$ vary with the selection institutions in both states as laid out above. First, the effects of the selection institutions in $\mathbf{A}$ are consistent across both aims. Increases in the size of the winning coalition in $\mathbf{A}$ and decreases in the size of its selectorate decrease the benefits of taking territory and increase the benefits of deposing $B$. Selection institutions in $\mathbf{A}$ that raise the benefits to $A$ of taking territory reduce the benefits of deposing $B$. The selection institutions of $\mathbf{B}$, on the other hand, have the same effect on the benefits of both types of war aims because both arise from the indirect benefit of reducing the resources that the leader of $\mathbf{B}$ allocates to foreign policy. Then we should expect that the results for the selection institutions of the target state $\mathbf{B}$ will be weaker than those for the selection institutions of $\mathbf{A}$.

So far we have considered the ends of territory and regime separately. $A$ also has the option of both taking territory and deposing $B$. As we showed earlier, the decision to seek both territory and regime changes has the structure of deciding to do both separately. Consequently, the effects of the selection institutions of $\mathbf{A}$ on whether $A$ chooses to pursue both types of war aims is contradictory; increases in the size of the winning coalition and decreases in the size of the selectorate in A make taking territory less attractive and deposing $B$ more attractive. Then we should expect that states with large or very small winning coalitions should be unlikely to pursue both territory and regime changes. The effects of the selection institutions of $\mathbf{B}$, on the other hand, are consistent, with increases in the winning coalition of the target state and decreases in the size of its selectorate increasing the chance that its opponent will pursue both types of war aims. The indirect benefits 
of each war aim are reduced when both are pursued. The benefit of changing the selection institutions of $\mathbf{B}$ to reduce the incentive of its leader to commit resources to foreign policy is less when you also reduce the resources of $\mathbf{B}$ by taking territory from it. We expect then that the pursuit of both war aims should be rare and is most likely to be pursued by states that have neither small nor large winning coalitions.

Now we turn to examine some evidence about these hypotheses.

\section{Testing the argument}

In Chapter 9 of The Logic of Political Survival, we test a less general version of the argument above against a variety of data sets of international conflict. For militarized disputes, we found that disputants who used violence were more likely to pursue territorial aims the smaller the winning coalition in their state and the larger the winning coalition in the target state. For major peace treaties, we found that the ratio of the number of articles addressing policy aims over those addressing private goods has increased over time, matching the increase in the size of the winning coalitions of states. For war outcomes, we found that victors with large winning coalitions were less likely to add territory as a result of the war and more likely to remove the enemy leader. Domestic removal of leaders during and after disputes is heavily influenced by whether the state is question wins the dispute, with winner less likely to be removed from office. Leaders who answer to a large winning coalition are almost certain to be removed if they lose the dispute, and their risk of removal increases if they use violence even if they win. Leaders who answer to a small winning coalition reduce their risk of removal if they also have a large selectorate or if they seek territorial gain and win. Finally, a victor who removes the defeated leader is much more likely to shrink a large winning coalition in the defeated state than increase a small winning coalition there.

Here we present some additional tests of the argument beyond those in the book. We now discuss our measures before turning to each of the new tests.

\section{Measures of selection institutions}

We use the well-known Polity collection of data (Marshall and Jaggers 2000) to create a crude indicator of the sizes of the winning coalition and selectorate in states. The broad coverage of Polity over space and time allows us to conduct large-n tests of our hypotheses. Rather than use the ten-point scales of democracy and autocracy commonly used in the literature, we create our own indices from specific components that Polity collects.

We estimate the size of $\mathrm{W}$ as a composite index based on the variables REGTYPE (regime type), XRCOMP (competitiveness of executive recruitment), XROPEN (openness of executive recruitment), and PARCOMP (competitiveness of participation) in Polity II. When REGTYPE is not missing data and is not equal to codes 2 or 3 in the Polity dataset, so that the regime type was not a military or military/civilian regime, we award one point to $\mathrm{W}$. When XRCOMP is larger than or equal to code 2 then another point is assigned to W. An XRCOMP code of 1 
means that the chief executive was selected by heredity or in rigged, unopposed elections, suggesting dependence on few people. Code values of 2 and 3 refer to greater degrees of responsiveness to supporters, indicating a larger winning coalition. XROPEN contributes an additional point to $\mathrm{W}$ if the executive is recruited in a more open setting than heredity (that is, the variable's value is greater than 2). Finally, one more point is contributed to $\mathrm{W}$ if PARCOMP is coded as a 5, meaning that "there are relatively stable and enduring political groups which regularly compete for political influence at the national level" (Marshall and Jaggers 2000, 18). We divide by the maximum value of 4 to normalize our indicator of $\mathrm{W}$ from 0 to 1 .

We use another Polity variable, Legislative Selection (LEGSELEC), as an indicator of S. In Polity this variable is coded as a trichotomy, with 0 meaning that there is no legislature. A code of 1 means that the legislature is chosen by heredity, ascription or is simply chosen by the effective executive. A code of 2 , the highest category, indicates that members of the legislature are directly or indirectly selected by popular election. We divide LEGSELEC by its maximum value of two so that it varies between 0 and 1 to facilitate comparisons with $\mathrm{W}$ and call it $\mathrm{S}$. These measures of selection institutions are crude, but they do allow tests across a large number of cases.

\section{Territorial aims in militarized disputes}

We first analyze when state leaders pursue territorial aims in militarized disputes. The Correlates of War project (COW) has collected a data set of militarized interstate disputes from 1815 to 1992 (Gochman and Maoz 1984; Jones et al. 1996). A militarized interstate dispute occurs whenever a state uses military force or threatens to use force (including displays of force) against another state. These events vary from minor threats by one state which do not provoke a response all the way to events as severe as the World Wars. We decompose disputes into pairs of states in conflict, called disputing dyads, and then break these dyads into pairs of directed dyads as we wish to see the effects of the selection institutions of both a disputant state and its opponent on war aims. ${ }^{2}$ For example, if France and Germany had a militarized dispute in 1895, we have two cases, France's aims against Germany and Germany's aims against France. Our analysis seeks to account for the motivations of these disputing states as coded by COW.

The COW project coded the motivations of disputing parties in terms first of whether the state sought any revision in the status quo, and if so, whether those revisions were primarily territorial, policy, or regime. In cases where a state had multiple goals, COW judged which was the principal objective of that state in the dispute. In some cases, a state's objective was ambigious; COW codes these cases as "other." States that did not seek revisions in the status quo are coded by COW as not having a goal in the crisis. According to our theory, these nonrevisionist states pursued the policy goal of preserving the status quo and are treated as such in our analysis.

2 EUGene (Expected Utility Generator), a program created by D. Scott Bennett and Allan Stam and available at www.eugenesoftware.org, was used in the construction of our dispute data and the decomposition into dyads. See Bennett and Stam (2000) for further details on EUGene. 
We are also interested in seeing whether the interest of leaders in territorial expansion changes with their power relative to the other in order to test the importance of the direct and indirect effects of territorial expansion. POWERRATIO measures the ratio of composite capabilities of the two states. A state's composite capabilities is the average of its share of the world total for each of six indicators, two demographic (population and urban population), two military (military personnel and military expenditures), and two industrial (iron/steel production and energy consumption). Our measure is just the composite capabilities of the state in question divided by the sum of the composite capabilities of both states, and so ranges from 0 to 1 with higher values indicating that the state in question is more powerful relative to its opponent. We also interact POWERRATIO with our measure of $\mathrm{W}$ in the state in question to see if the relationship between selection institutions and territorial aims changes with relative power. Recall that a leader of a large W system might seek territorial expansion if it is weaker than its opponent as a way to shift the balance of power between the two.

We also include two control variables. LANDCONTIG is whether the two states share a land border. POST 45 is whether the dispute occurs after 1945 when some argue that a norm of territorial integrity has existed in world politics (e.g. Zacher 2001). ${ }^{3}$

Table 1 presents the results of two logit analyses of whether disputing states sought territory in a militarized dispute. The standard errors were calculated with clustering on the dispute in question because the separate directed dyads in each dispute are not independent observations. The significance probabilities reported in the table are for one-tailed tests of the hypotheses. Decreases in the winning coalition of the state or increases in the size of its selectorate make its leader more likely to pursue territorial aims in a militarized dispute. A state is also more likely to seek territory the larger the size of the winning coalition and the smaller the size of the selectorate of the target state. In both cases, the coefficient for the winning coalition is several times larger than that of the selectorate. The theory predicts that the effect of the size of the winning coalition should be larger than that of the selectorate; however, the ordinal nature of our measures of both concepts make that inference dubious.

The second model includes an interaction between the size of the winning coalition in the disputant state and the ratio of capabilities of the two disputants. This analysis seeks to ascertain the indirect effect of territorial expansion on security by shifting the balance of power. The ratio of capabilities could have two effects of the willingness to take territory according to the model. First, the stronger a state is compared to its opponent, the lower its costs for taking territory. Second, the weaker a state is compared to its opponent, the greater the indirect benefit of reducing the

\footnotetext{
3 At the suggestion of David DeJong at the conference, we divided the data at 1945 and ran a separate analysis on each to examine the full effects of any possible regime shift at that point in time. The effect of the size of winning coalition becomes stronger in the post-1945 period, but is no longer statistically significant for the earlier period. The interaction between power and the size of the winning coalition has the same sign in both periods, with states with large winning coalitions being less likely to take territory as they become stronger relative to their opponent. States facing opponents with large winning coalitions are more likely to seek territory in both periods.
} 
Table 1. Logit analysis of when leaders pursue territory in disputes

\begin{tabular}{|c|c|c|}
\hline Variable & Base model & Model with interaction \\
\hline Size of winning coalition & $\begin{array}{l}-0.91 \\
0.31 \\
0.0015\end{array}$ & $\begin{array}{l}-0.33 \\
0.28 \\
0.12\end{array}$ \\
\hline Size of selectorate & $\begin{array}{l}0.33 \\
0.20 \\
0.05\end{array}$ & $\begin{array}{l}0.33 \\
0.20 \\
0.05\end{array}$ \\
\hline Size of opponent's winning coalition & $\begin{array}{c}1.22 \\
0.19 \\
<0.001\end{array}$ & $\begin{array}{c}1.21 \\
0.19 \\
<0.001\end{array}$ \\
\hline Size of opponent's selectorate & $\begin{array}{c}-0.27 \\
0.15 \\
0.037\end{array}$ & $\begin{array}{c}-0.24 \\
0.15 \\
0.055\end{array}$ \\
\hline Ratio of composite capabilities & $\begin{array}{l}0.17 \\
0.17 \\
0.16\end{array}$ & $\begin{array}{l}0.84 \\
0.39 \\
0.017\end{array}$ \\
\hline $\begin{array}{l}\text { Interaction of ratio of composite } \\
\text { capabilities and size of winning } \\
\text { Coalition }\end{array}$ & & $\begin{array}{r}-1.25 \\
0.57 \\
0.014\end{array}$ \\
\hline Disputants share land border? & $\begin{array}{c}1.32 \\
0.16 \\
<0.001\end{array}$ & $\begin{array}{c}1.29 \\
0.17 \\
<0.001\end{array}$ \\
\hline Dispute after $1945 ?$ & $\begin{array}{r}-0.38 \\
0.16 \\
0.007\end{array}$ & $\begin{array}{r}-0.37 \\
0.16 \\
0.01\end{array}$ \\
\hline \multirow[t]{2}{*}{ Constant } & -2.35 & -2.65 \\
\hline & $\begin{array}{c}N=4163 \\
\Pi^{2}=210.68(7 \text { d.f. }) \\
p<0.001 \\
\text { Pseudo } R^{2}=0.08\end{array}$ & $\begin{array}{c}N=4164 \\
\Pi^{2}=213.11(8 \text { d.f. }) \\
p<0.001 \\
\text { Pseudo } R^{2}=0.08\end{array}$ \\
\hline
\end{tabular}

capabilities of the opponent by taking territory. States with a small winning coalition should not place much weight on the second effect of the ratio of capabilities, and so be more likely to take territory the stronger they are relative to their target. States with a large winning coalition are more interested in taking territory when they are weaker than their opponent as a way to increase their own security. We cannot say which effect is larger for states with large winning coalition, although we can say that the interaction of power ratio and size of winning coalition should be negative. The second model in Table 1 includes this interaction, and the results are consistent with the expectations from the model. States with small winning coalitions are more willing to seek territory the stronger they are relative to their target. States with large winning coalitions are more willing to seek territorial gain the weaker they are relative to their target.

The coefficient for the size of the winning coalition alone is not significant in the model with the interaction because the interactive term captures some of its effect. To show that the willingness to take territory decreases as the size of the winning 
Table 2. Estimated probability of territorial aims from interactive model for illustrative cases

\begin{tabular}{|c|c|c|c|c|}
\hline \multirow[t]{2}{*}{ State's Selection Institutions } & \multirow{2}{*}{$\begin{array}{l}\text { Opponent's selection } \\
\text { institutions }\end{array}$} & \multicolumn{3}{|c|}{ Power ratio } \\
\hline & & Weaker & Equal & Stronger \\
\hline \multirow[t]{3}{*}{ Modern mass democracy } & Modern mass democracy & 0.377 & 0.353 & 0.330 \\
\hline & $\begin{array}{l}\text { Military dictatorship or } \\
\text { traditional monarchy }\end{array}$ & 0.187 & 0.172 & 0.157 \\
\hline & One-party autocracy & 0.248 & 0.230 & 0.212 \\
\hline \multirow{3}{*}{$\begin{array}{l}\text { Military dictatorship or } \\
\text { traditional monarchy }\end{array}$} & Modern mass democracy & 0.455 & 0.507 & 0.560 \\
\hline & $\begin{array}{l}\text { Military dictatorship or } \\
\text { traditional monarchy }\end{array}$ & 0.240 & 0.281 & 0.325 \\
\hline & One-party autocracy & 0.313 & 0.360 & 0.410 \\
\hline \multirow[t]{3}{*}{ One-party autocracy } & Modern mass democracy & 0.457 & 0.471 & 0.484 \\
\hline & $\begin{array}{l}\text { Military dictatorship or } \\
\text { traditional monarchy }\end{array}$ & 0.242 & 0.252 & 0.262 \\
\hline & One-party autocracy & 0.315 & 0.327 & 0.339 \\
\hline
\end{tabular}

For the calculations in this table, modern mass democracies have $W=1$ and $S=1$, military dictatorships or traditional monarchies have $W=0$ and $S=0$, and oneparty autocracies have $W=1 / 2$ and $S=1$. The power ratio is assumed to be $1: 3$ $($ POWERRATIO $=0.25)$ in the weaker column, $1: 1($ POWERRATIO $=0.5)$ in the equal column, and 3:1 (POWERRATIO =0.75) in the stronger column. The calculations also assume the states share a land border (LANDCONTIG =1) and the dispute occurred before 1945 (POST $45=0$ ) in order to maximize the chance that the state would have territorial aims.

coalition increases, Table 2 gives estimated probabilities of territorial aims for a range of suggestive values of the variables. We use three ideal types of systems: a modern, mass democracy where both the winning coalition and selectorate are large $(\mathrm{W}=1$ and $\mathrm{S}=1)$, a traditional monarchy or military dictatorship where both the winning coalition and selectorate are small ( $\mathrm{W}=0$ and $\mathrm{S}=0$ ), and a modern, one-party autocracy where the winning coalition is small but still larger than in the previous system and the selectorate is large $(\mathrm{W}=1 / 2$ and $\mathrm{S}=1) .{ }^{4}$ We have set the control variables to maximize the chance that the state in question will have territorial aims and then show different combinations of the selection institutions of both states and the ratio of their capabilities. Even with the interactive term, the selection institutions of both states have the effect predicted by the model. Leaders who answer to a large winning coalition are less likely to seek territory in conflict, and their states are more likely to be the targets of territorial demands.

\section{Overthrowing enemy regimes}

According to our arguments, leaders seek to overthrow enemy leaders to solve a post-war commitment problem with securing the cooperation of the defeated state

\footnotetext{
4 These happen to be the values of our measures for Nazi Germany.
} 
with the policy aims of the victor. They do not begin the dispute to overthrow the enemy leader; they only come to this end in order to guarantee their policy aims after the dispute is over. Our test then must be on a more limited set of cases than the full set of militarized disputes. We first limit our set of test cases to those disputants who had policy aims. We consider a state to have policy aims if COW coded their aims in the dispute as either policy or regime because our argument considers regime aims to be motivated to secure the underlying policy aims. We ask then which of the states with policy aims decided to seek the removal of the enemy leader to secure those aims.

We also limit the analysis to disputes where both sides used force. First, we require the state in question to use force because otherwise we may include cases where one side declared its intent was to overthrow the regime of its target even though the former had no intention of pursuing that aim at the required cost. We also require the target to use force as well. Unlike demands for territory, it is unlikely that the leader of a target state will yield to demands for regime change without a fight. War aims to overthrow the enemy regime, according to our argument, should only occur in the most pronounced policy disputes, those where the target is unwilling to make the concessions and where the threatening state is concerned that the target will not live up to those concessions afterwards even if it is forced to make them. Our analysis then asks in which of these serious policy disputes was the commitment problem seen as large enough to justify a serious attempt to remove the leader of the target state. ${ }^{5}$

These restrictions on the set of cases to be analyzed raise the issue of selection bias because selection institutions of both sides should be correlated with their willingness to use force against one another. We address the question of selection bias by running a Heckman analysis where the selection equation estimates the likelihood that both sides use force and the outcome equation then whether the state in question had regime aims in the dispute. The selection equation includes the sizes of the winning coalitions of both side and their interaction to reflect that states with large winning coalitions are much less likely to escalate to mutual violence (the result known to most as the democratic peace). We also include land contiguity in the selection equation because disputes involving states that share a border are more likely to escalate to mutual use of force.

As with our analysis of territorial aims, we include the selection institutions of both states but we include the interaction of the sizes of their winning coalition with the power ratio as well. Table 3 presents the results of two analyses. The first uses our standard measures of $\mathrm{W}$ and $\mathrm{S}$. The second analysis uses a variant where the size of the selectorate is replaced by the effective size of the selectorate, which is $\mathrm{S}(1-\mathrm{W})$. This measure tries to represent the idea that the size of the selectorate has the most effect when leaders provide substantial private benefits, that is, when $\mathrm{W}$ is small. The risk of exclusion looms large in the minds of the leader's supporters when

5 We also ran a Heckman analysis using just the use of force by the threatening state as the selection condition, rather than joint violence. The results are similar but weaker than those we report. An examination of the cases shows a number of disputes where only one side used force and had regime aims were clearly not serious efforts to remove the enemy regime. 
they receive private benefits, making the size of the pool of possible replacements for them, the selectorate, more important.

At first glance, the results in Table 3 support our argument weakly. Leaders are more likely to pursue removal of the enemy regime the larger the winning coalition of the target state, but the size of their own winning coalition has the opposite effect from that predicted by our argument. However, selection institutions enter the estimates in several places, and so Table 4 shows the estimated probabilities of regime aims for representative values of the variables. Now a pattern of evidence consistent with our argument emerges. First of all, states rarely seek to overthrow the enemy's regime; the highest estimated probability of regime aims is slightly above $1 / 4$, which occurs for a stronger democracy against a one-party autocracy. The highest probabilities of regime aims occur between the two types of systems democracies and one-party autocracies - that have larger winning coalitions. Mass democracies do not seek to replace leaders who answer to a small winning coalition. The fact that large winning coalition systems do not fight one another may lead to our inability to observe whether leaders of such systems would seek to replace one another if they fought. Willingness to adopt regime replacement as a war aim does seem to rise with the power ratio, suggesting that stronger states are more willing to adopt such aims as the cost of doing so goes down. The exception occurs when a large winning coalition system is the target, but such states rarely lose, so it is not clear that such aims have a realistic chance of be realized.

\section{The pursuit of both territory and regime}

States should pursue both territorial acquisition and the overthrow of the enemy regime rarely, according to our model. Further, leaders who answer to a middlesized winning coalition, neither small nor large, should be most likely to do so. The militarized dispute data that we used above is not well-suited to test these hypotheses because COW sought to code only one aim for each party in a dispute. Instead, we turn to the outcomes of war using a data set we assembled from several different COW collections. We matched the victors of the Interstate War data to the Territorial Change data (Goertz and Diehl 1992, Tir et al 1998) and our own collection of leader data (Bueno de Mesquita et al 2003) to determine when victors in war added territory or overthrew the enemy leader as a consequence of their victory. ${ }^{6}$ Fortunately for mankind, but unfortunately for our analysis, war is rare and so there are not a large number of victors in wars since 1815 . The rarity of the data makes multivariate analysis like that above impossible to carry out. Instead, Table 5 presents the size of the winning coalition in victorious states against how often they added territory beyond their prewar borders and overthrew the enemy leader.

Two conclusions follow from Table 5. First, very few victors have both added territory and overthrown the enemy leader. Of our 382 victorious states in interstate wars since 1815 , only 5 have added territory and overthrown the enemy leader.

\footnotetext{
${ }^{6}$ Full details of our procedure can be found on pp. 434-437 of Bueno de Mesquita et al (2003). The data set is available at http://sitemaker.umich.edu/jdmorrow/data_sets.
} 
Table 3. Heckman analysis of when leaders with policy aims seek to depose enemy leader in disputes

\begin{tabular}{|c|c|c|}
\hline Variable & Base model & $\begin{array}{l}\text { Model with alternate } \\
\text { measure of selectorate }\end{array}$ \\
\hline Size of winning coalition & $\begin{array}{c}-0.91 \\
0.33 \\
\text { (wrong sign) }\end{array}$ & $\begin{array}{c}-0.17 \\
0.36 \\
\text { (wrong sign) }\end{array}$ \\
\hline Size of selectorate & $\begin{array}{c}0.66 \\
0.21 \\
\text { (wrong sign) }\end{array}$ & \\
\hline Effective size of selectorate & & $\begin{array}{c}0.82 \\
0.28 \\
\text { (wrong sign) }\end{array}$ \\
\hline Size of opponent's winning coalition & $\begin{array}{l}0.87 \\
0.32 \\
0.004\end{array}$ & $\begin{array}{l}0.78 \\
0.31 \\
0.006\end{array}$ \\
\hline Size of opponent's selectorate & $\begin{array}{r}-0.06 \\
0.17 \\
\text { n.s. }\end{array}$ & \\
\hline Effective size of opponent's selectorate & & $\begin{array}{c}-0.09 \\
0.23 \\
\text { n.s. }\end{array}$ \\
\hline Ratio of composite capabilities & $\begin{array}{l}0.62 \\
0.34 \\
0.037\end{array}$ & $\begin{array}{l}0.56 \\
0.34 \\
0.048\end{array}$ \\
\hline $\begin{array}{l}\text { Interaction of ratio } \\
\text { of composite capabilities and size of winning } \\
\text { Coalition }\end{array}$ & $\begin{array}{l}0.49 \\
0.46 \\
0.14\end{array}$ & $\begin{array}{c}0.58 \\
0.47 \\
.11\end{array}$ \\
\hline $\begin{array}{l}\text { Interaction of ratio of composite } \\
\text { capabilities and size of opponent's } \\
\text { winning coalition }\end{array}$ & $\begin{array}{c}-1.21 \\
0.49 \\
0.007\end{array}$ & $\begin{array}{c}-1.20 \\
0.48 \\
0.006\end{array}$ \\
\hline Constant & -2.35 & -1.30 \\
\hline \multicolumn{3}{|l|}{$\begin{array}{l}\text { Selection equation: Did both sides } \\
\text { use violence? }\end{array}$} \\
\hline Size of winning coalition & 0.50 & 0.50 \\
\hline Size of opponent's winning coalition & 0.30 & 0.30 \\
\hline Disputants share land border? & 0.50 & 0.50 \\
\hline $\begin{array}{l}\text { Product of sizes of winning coalitions } \\
\text { of both sides }\end{array}$ & -.78 & -.78 \\
\hline Constant & -1.09 & -1.09 \\
\hline \multirow[t]{2}{*}{ Rho (correlation of error terms) } & -.48 & -.48 \\
\hline & $\begin{array}{c}N=3980 \\
\text { Uncensored } N=987 \\
\Pi^{2}=17.09(7 \text { d.f. }) \\
p=0.017\end{array}$ & $\begin{array}{c}N=3980 \\
\text { Uncensored } N=987 \\
\Pi^{2}=16.89(7 \text { d.f. }) \\
p=0.018\end{array}$ \\
\hline
\end{tabular}


Table 4. Estimated probability of regime aims given policy aims for illustrative cases from base model

\begin{tabular}{|c|c|c|c|c|}
\hline \multirow[t]{2}{*}{ State's selection institutions } & \multirow{2}{*}{$\begin{array}{l}\text { Opponent's selection } \\
\text { institutions }\end{array}$} & \multicolumn{3}{|c|}{ Power ratio } \\
\hline & & Weaker & Equal & Stronger \\
\hline \multirow[t]{3}{*}{ Modern mass democracy } & Modern mass democracy & 0.140 & 0.137 & 0.134 \\
\hline & $\begin{array}{l}\text { Military dictatorship or } \\
\text { traditional monarchy }\end{array}$ & 0.060 & 0.052 & 0.048 \\
\hline & One-party autocracy & 0.226 & 0.249 & 0.273 \\
\hline \multirow{3}{*}{$\begin{array}{l}\text { Military dictatorship or } \\
\text { traditional monarchy }\end{array}$} & Modern mass democracy & 0.156 & 0.138 & 0.121 \\
\hline & $\begin{array}{l}\text { Military dictatorship or } \\
\text { traditional monarchy }\end{array}$ & 0.100 & 0.115 & 0.132 \\
\hline & One-party autocracy & 0.104 & 0.105 & 0.105 \\
\hline \multirow[t]{3}{*}{ One-party autocracy } & Modern mass democracy & 0.195 & 0.172 & 0.169 \\
\hline & $\begin{array}{l}\text { Military dictatorship or } \\
\text { traditional monarchy }\end{array}$ & 0.127 & 0.153 & 0.180 \\
\hline & One-party autocracy & 0.154 & 0.162 & 0.172 \\
\hline
\end{tabular}

For the calculations in this table, modern mass democracies have $W=1$ and $S=1$, military dictatorships or traditional monarchies have $W=0$ and $S=0$, and oneparty autocracies have $W=1 / 2$ and $S=1$. The power ratio is assumed to be $1: 3$ $($ POWERRATIO $=0.25)$ in the weaker column, $1: 1($ POWERRATIO $=0.5)$ in the equal column, and 3:1 (POWERRATIO $=0.75)$ in the stronger column.

Table 5. Cross-tabulation of the size of the victor's winning coalition with whether it added territory and overthrew the defeated leader

\begin{tabular}{cccc}
\hline & \multicolumn{2}{c}{ Size of winning coalition } \\
\hline Added territory and overthrew enemy leader? & Very small & Middle-sized & Large \\
No & 166 & 62 & 149 \\
Yes & $1(0.6 \%)$ & $3(4.6 \%)$ & $1(0.7 \%)$ \\
\hline
\end{tabular}

Second, states with middle-sized winning coalitions are more likely to do so than those with small or large winning coalitions. The difference in frequency between the states with middle-sized winning coalitions and all others is significant at the .01 level using a test of binomial proportions. ${ }^{7}$

\footnotetext{
7 The two conclusions are robust against two variations in the codings of adding territory and overthrowing enemy leaders. Our data set also includes postwar territorial changes that restore prewar borders and changes in enemy leaders produced by new institutions installed by the victor. Both of these changes are dropped in Table 5. If they are both included, the only change in the Table is that 4 of the 150 victors with large winning coalitions added territory and overthrew the enemy leader. An example of this is France at the end of the Second World War as the Nazi regime was overthrown and France regained Alsace-Lorraine which Germany had annexed earlier in the Second World War.
} 


\section{Discussion}

Our efforts are not the first to examine the question of war aims, although other efforts do not address the question of territorial aims versus regime aims. Other work seeks to examine bargaining during wartime and how the course of fighting influences the settlement reached to end the war (Wagner 2000). Filson and Werner (2004) present a model of bargaining during wartime which leads to the conclusion that democracies - states with large winning coalitions in our argument - should receive less attractive settlements. These and other papers (Slantchev 2004, Werner 1998) share the assumption that the postwar settlement ends the issue and so the parties do not need to worry about winning the peace afterwards. Instead, they focus on how battle outcomes shift the bargains that the parties would accept. Goemans (2000) does consider the commitment problem involved in winning the peace but only in terms of how the postwar balance of capabilities affects the stability of the postwar settlement.

Even with this limitation, the empirical results in Werner (1998) have some relevance to our argument. She coded war settlements on a five-point scale assessing how favorable the settlement was for the state that won the war, ranging from a return to the prewar status quo through conquest of the loser or removal of the losing leader. She found no statistically significant relationship between the harshness of the settlement and the regime type of either the winner or loser. Our argument suggests that the pattern should be nonlinear with large winning coalition systems - democracies in the regime type measure - being more likely to accept lesser settlements and seek a harsh conclusion than systems with smaller winning coalitions. If true, this pattern would lead to a poor fit between linear relationship and the data.

Grieco (2001) provides the clearest match with our argument and the strongest support for it. He examined the duration of peace following militarized disputes using a duration analysis, providing a direct comparison with our argument about the stability of postwar settlements. Among his results, democratic challengers are much more likely to renew a challenge to the status quo after a dispute, consistent with our argument that defeated states with large winning coalitions are more likely to seek to overturn the consequences of defeat. Further, democratic defenders are also more likely to suffer renewed challenges unless they prevailed through the use of force. These results are consistent with our argument about how selection institutions exacerbate the commitment problem involved in winning the peace.

\section{Conclusion}

In this paper, we lay out our argument about how the selection institution of a state influence the war aims pursued by its leader. The larger the winning coalition, the less interest the leader has in territorial expansion and the more likely the leader will see removal of the enemy leader as a solution to the commitment problem posed by policy aims. Increasing the selectorate while holding the winning coalition constant has the opposite effect. Similarly, the selection institutions of the opponent also influence a state's war aims. An enemy with a larger winning coalition is more 
likely to use its power after the war to thwart the victor's policy aims, so increases in the size of its winning coalition lead the other state to be more likely to seek to take territory from it and to overthrow its leader. The relative power of the two sides interacts with their selection institutions. States with large winning coalitions are more likely to seek to take territory when they are weaker than their opponent; this helps to reduce the imbalance in power between the two. Such states are also more likely to seek to overthrow the enemy leader when they are stronger than the enemy state because the costs of deposition are lower.

Our model does not endogenize the choice of whether to go to war. Clearly, the likelihood of war depends on selection institutions as we show in Chapter 6 of our book. An obvious extension of our model would be to include the joint decision to go to war. Because states with large winning coalitions are more likely to win wars, they make less attractive targets. However, the leaders of such systems are more cautious about choosing to fight because they fear the consequences for their hold on power should they lose. Consequently, they are more willing to make concessions to avoid war except when they are confident of victory. Their willingness to make concessions to avoid war makes them attractive targets for coercive threats, particularly by states whose leaders answer to small winning coalitions. Such leaders' hold on power increases if they pursue territory and prevail in a crisis. This line of reasoning provides an explanation of why autocracies and democracies are more likely to fight than other pairs of states; the autocrats seek concessions from the democrats, who choose to fight when they believe they will win.

Finally, our argument suggests some patterns in the long-term history of international politics. Historically, there has been a long movement since absolutism in Europe to modern mass democracy. These shifts in selection institutions, first through constitutional monarchy with legislatures selected by a small set of the citizens and later through expansion of suffrage and the dominance of elected leaders over monarchs, have changed the issues at contest in world politics. Territory was the issue in contest in the era of absolute monarchs because monarchs relied on a small winning coalition drawn from the aristocracy. As monarchs became subject to constitutional limitations and then replaced by elected prime ministers or presidents, territory receded as an issue for systems with such leaders. The other broad type of political system to emerge as monarchy receded was the one-party autocracy; these leaders still sought territory, and the leaders of such systems triggered the two World Wars. We speculate that the spread of systems with large winning coalitions was key to the decline of territory as an issue of dispute and the rise of the norm of territorial integrity noted by others (Zacher 2001). The move to larger winning coalitions had another less appreciated effect; the norm of non-intervention - the idea that state leaders should not seek to overthrow one another - receded. We plan to address these patterns in detail in future research.

\section{Appendix}

Please see http://sitemaker.umich.edu/jdmorrow/files/berlinapp.pdf 


\section{References}

Bennett, D.S., Stam A. (2000) EUGene: A conceptual manual. International Interactions 26(2), 179-204 Bueno de Mesquita, B., Smith, A., Siverson, R.M., Morrow J.D. (2003) The Logic of Political Survival. MIT Press, Cambridge, MA

Filson, D, Werner, S. (2004) Bargaining and fighting: The impact of regime type on war onset, duration, and outcomes. American Journal of Political Science 48(2), 296-313

Gochman, C.S., Maoz Z. (1984) Militarized interstate disputes, 1816-1976: Procedures, patterns, and insights. Journal of Conflict Resolution 28(4), 585-616

Goemans, H.E. (2000) War and Punishment. Princeton University Press, Princeton, NJ

Goertz, G., Diehl P. (1994) Territorial Changes and International Conflict. London, Routledge

Grieco, J.M. (2001) Repetitive military challenges and recurrent international conflicts, 1918-1994. International Studies Quarterly 45(2), 295-316

Jervis, R. (1978) Cooperation under the security dilemma. World Politics 30(2), 167-214

Jones, D.M., Bremer, S.A., Singer, J.D. (1996) Militarized interstate disputes, 1816-1992: Rationale, coding rules, and empirical patterns. Conflict Management and Peace Science 15(2): 163-213

Lake, D.A. (1999) Entangling Relations: American Foreign Policy in Its Century. Princeton University Press, Princeton, NJ

Marshall, M.G., Jaggers, K. (2000) Polity IV Project: Dataset Users' Manual. University of Maryland, College Park, MD

Slantchev, B. (2004) How initiators end their wars: The duration of warfare and the terms of peace. American Journal of Political Science 48(4), 813-829

Tir, J., Schafer, P., Diehl, P.F., Goertz, G. (1998) Territorial changes, 1816-1996. Conflict Management and Peace Science 16(1), 89-97

Wagner, R.H. (2000) Bargaining and war. American Journal of Political Science 44(3), 469-484

Werner, S. (1998) Negotiating the terms of settlement: War aims and bargaining leverage. Journal of Conflict Resolution 42(3), 321-343

Zacher, M.W. (2001) The territorial integrity norm: International boundaries and the use of force. International Organization 55(2), 215-250 